\title{
Water And Other Drinks Consumption Evaluation In Kuwait
}

Jasem M. Alhumoud, (E-mail: jasem@ civil.kuniv.edu.kw), Kuwait University, Kuwait Jaber Al-Medij, Kuwait University, Kuwait

\begin{abstract}
The problem of securing and gaining reliable water supplies has been an issue of great importance to the people of Kuwait, ever since the earliest days of settlement in the region. The main objective of this paper is to analyze the Kuwaitis' attitudes concerning water and other drinks consumption. A simple, yet structured questionnaire, which provides the data base for the study was designed, presented, and employed in a person-survey of a random sample of 2,500 individuals residing in the six governorates of Kuwait. The frequency distribution of the type of water (tap, filter and/or bottled), number of classes of water, number of classes of other drinks, and other socio-economic characteristics of the sample population are presented. Results show that although an overwhelming majority of Kuwaitis know that drinking water is health enhancing, most do not drink as much per day as they should. Results also show that people in Kuwait consume a lot of dehydrating drinks. More importantly, this research establishes a baseline of information about public opinion, knowledge, and behavior regarding drinking water and other drinks, so that the impact of public education programs, in particular, may be assessed and measured in the future.
\end{abstract}

\section{INTRODUCTION}

$c$

overing an area of $17,818 \mathrm{~km}^{2}$, Kuwait lies in the north western region of the Arabian Gulf. Kuwait's mainland extends between latitudes $28^{\circ} 30^{\prime}$ and $30^{\circ} 06^{\prime}$ north, longitudes $46^{\circ} 30^{\prime}$ and $48^{\circ} 30^{\prime}$ east and measures about $200 \mathrm{~km}$ from the farthermost northern to the farthermost southern points and about $170 \mathrm{~km}$ from east to west between the extreme longitudes.

The per capita income in Kuwait is about \$16,800 therefore, Kuwait provides its citizens with extensive health, educational, and retirement benefits. In 1999 the per capita gross domestic product (GDP) was \$16,244 and the growth rate of that was 10.5 percent. The gross national product (GNP) was $\$ 17,390$ and the average annual growth of the GNP per capita -3.5 percent (MOP, 2003).

The State of Kuwait consists of six governorates. The registered population of the country as of the year 2000 is 2.23 million and population density of 140 per $\mathrm{km}^{2}$, where about 0.83 million are Kuwaiti citizens and 1.4 million are foreigners, and the population growth rate is reported to be $6.25 \%$ per year.

Because of its location, the weather of the country is typical of a desert (arid) region. Kuwait receives only about $100 \mathrm{~mm}(3.94 \mathrm{in})$ of rain annually. This precipitation is highly variable from year to year $(40-240 \mathrm{~mm})$ and ground water is scarce, thus complicating water development efforts (MOP, 2003). The main sources of water in Kuwait and the other Gulf Cooperation Council (GCC) States are either from desalination of seawater or from groundwater aquifers. Over half of the global desalination capacity is utilized in the GCC States. The GCC States installed desalination capacity is currently in excess of five gega liters per day (5 glpd) (Al-Sofi, 1994; Al-Zubari, 1998; Alhumoud et. al. 2003). In the past, the people of Kuwait relied on a scant number of wells to satisfy their water needs. Water from those wells accompanied with fresh water transported by boats from Basra, Iraq, were the main source of water supply to the people. Transporting water by boats continued for some time, and in 1939 a company was established to manage the fleet of water carriers from Iraq. At the time, three reservoirs were constructed on the 
shore for water storage. The first major breakthrough came in 1951 when the Kuwait Oil Company (K.O.C) built a small seawater desalination plant with a capacity of 80,000 gallon per day at the port of al-Ahmadi (Mina AlAhmadi), and it distributed part of the water to the town of Kuwait. The first major desalination plant was build in 1953 with a capacity of 1 million gallons per day (mgpd). In 1978 another desalination plant was build in Doha. The capacity of the Doha plant is 42 mgpd (ME 2003, Alhumoud 2003).

The country was and still is very anxious to exploit all available groundwater, both freshwater for drinking and brackish water for irrigation. As for fresh groundwater, it is considered a matter of prime importance. Fresh groundwater was discovered in limited quantities at both Al-Rawdhatain and Umm Al-Aish fields. Pumping operations commenced in 1962, whereas the estimated natural reserve of both fields is about 40,000 million gallons. In 1980 the Rawdhatain Water Production and Bottling Projects started to produce $1800 \mathrm{~m}^{3} /$ year of mineral water. The Umm Al-Aish field is currently producing $8000 \mathrm{~m}^{3} /$ year of mineral water (Omer et. al. 1996 and Alhumoud 2003).

Besides freshwater the country makes use of its large supply of brackish groundwater. The authority distributes this water to the consumers through separate networks parallel to the freshwater network. The brackish water is intended to be used for various purposes, such as blending with distilled water, irrigation, livestock watering and construction works. The consumption of fresh and brackish water has been increasing with the increase of the population, naturally. As it is noticed from both tables the average consumption of both types of water is increasing gradually with the exception of the years 1990 and 1991. This decrease is explained by the invasion of Iraq and the start of the Gulf war. It is worth mentioning that. The number of consumers connected to the fresh water network totaled 94,488 by the year 1997 , while consumers connected to the brackish water network totaled 63,047 by the end of the same year (ME 2003).

As it is noticed from Fig. 1 the average consumption of water is increasing gradually with the exception of the years 1990, 1991 and 1992. This decrease is explained by the invasion of Iraq and the start of the Gulf war. During that period, water production was interrupted tremendously. In addition, the population was at it lowest levels, due to the large exodus/immigration of the people from the country. In addition, Fig. 2 shows the per capita consumption of fresh water in Kuwait. It is shown from the figure that the per capita consumption is increasing yearly as well, with a slight drop during 1998. The data for the years 1990 and 1991 is unavailable and missing. As mentioned earlier, this was due to the Gulf War. The per capita consumption is increasing at an alarming rate, for example, in the year 1980 it was 45.7 IG, in 1994 it was 95 IG and in 2003 it was 117 IG. This could be explained by the increase in the standards of living of people and some changes in their life style, such as, the emergence of gyms, health clubs, and people attention to health matters coupled with the lack of enforcement of water bills collection. From 1992 up to the present time the Ministry of Energy (ME) has not collected water bills from residents. The current per capita water consumption is significantly higher when compared to Western Europe, North Africa, North America and some of the countries in the Gulf Region (Figure 3) (KEPS, 2004). By the end of the year 2000 the total length of the entire water network was $131,45 \mathrm{Km}$. It is worth mentioning that, the number of consumers connected to the fresh water network totaled 111,581 by the year 2000, while consumers connected to the brackish water network totaled 67,657 by the end of the same year (ME, 2003).

In the affluent State of Kuwait, nearly 98 percent of the population resides in Metropolitan Kuwait. A unique characteristic of Kuwait and other nations of the Gulf Cooperation Council (GCC) is the constant change in the expatriate population from year to year. Each year, a significant percentage of Kuwait's expatriate population, which constitutes $62 \%$ of Kuwait's population; leaves the State upon termination of their contracts. These individuals are replaced by other incoming expatriate workers mostly from Egypt, India, Bangladesh, and Sri Lanka (Koushki and Alhumoud, 2002). 


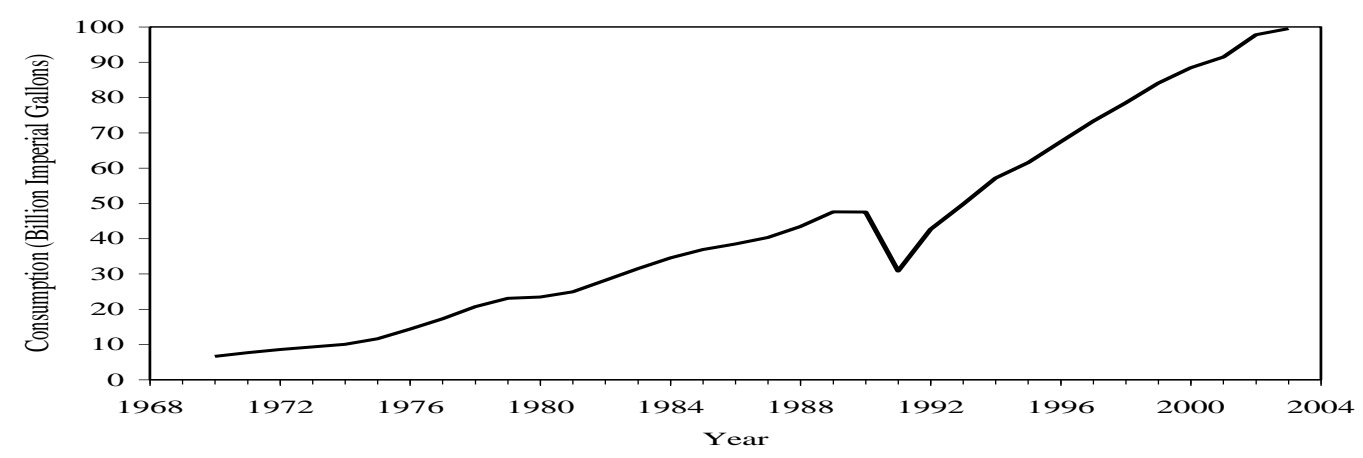

Figure 1. Fresh Water Consumption (1970-2003)

There are many different brands (regional and national) of bottled water available in the country, but Al-Rawdatin is the only brand that is produced and bottled in Kuwait. The name Al-Rawdatin is taken after the Al-Rawdatin fresh groundwater aquifer located in the north of the country. Besides water, the people in Kuwait consume a lot of other beverages, hydrating and dehydrating. Hydrating beverages include water, juice, milk, and carbonated soda without caffeine. On the other hand, dehydrating beverages include coffee, tea, and carbonated soda with caffeine. Even though alcoholic drinks are considered dehydrating beverages, they are not included in this study since they are illegal and are forbidden from being consumed in the state of Kuwait.

\section{RESEARCH METHOD}

Following a comprehensive review of the related literature and the establishment of an organizational structure for the implementation of the research, a survey plan was designed. The computation of the sample size, development of a questionnaire, determination of a sampling technique and sample population were all addressed in the survey design. The computation of the sample size was made in accordance with the commonly utilized statistical equation (Walpole and Myers 1985). A confidence level of 95\%, and an error level of $\pm 5 \%$ were considered to be appropriate by the research team. By utilizing a recommended value of 0.5 for the standard deviation (for maximum possible standard error of the mean), the minimum required sample size may be computed from the following equation:

$$
\sqrt{\mathrm{N}}=\left[\left(\mathrm{Z}_{1-\alpha / 2} * \mathrm{~S}\right) / \mathrm{e}\right]
$$

where:

$\mathrm{N}=$ the minimum required sample size.

$\mathrm{Z}=$ the number of units of the standard deviation in a standard normal distribution curve $(\mathrm{Z}=1.96, \alpha=5 \%)$.

$\alpha=$ significance level.

$\mathrm{S}=$ standard deviation ( 0.5 when the true population standard deviation is not known).

e $\quad=$ acceptable error $( \pm 5 \%)$. 
Equation 1 and the above input values result in a minimum sample size of 385.

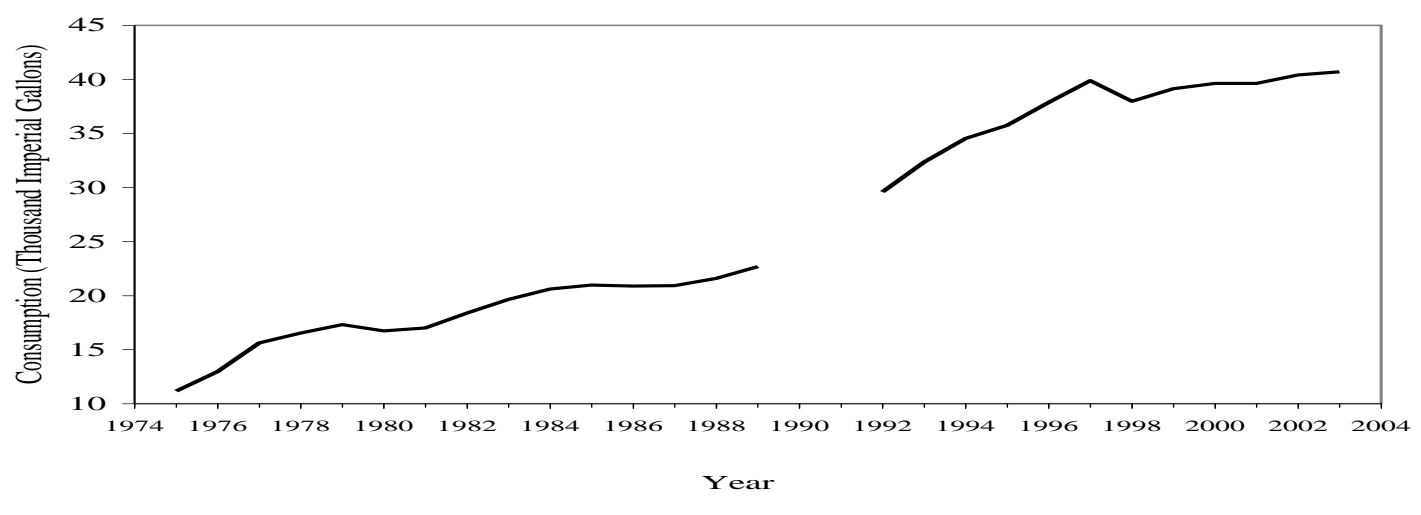

Figure 2. Per capita consumption of fresh water (1975-2003).

A simple yet structured questionnaire was designed, and pre-tested to obtain information on households' socio-economic traits, and residence characteristics as well as the daily water-consuming activities of sample households. After being pre-tested and modified, the questionnaire was distributed to a systematic-random sample of 3000 households residing in the six governorates of Metropolitan Kuwait. Special care was taken to ensure the representativeness of various socio-economic groups in the sample. A total of 2,050 completed questionnaires were processed for analysis. The data were compiled in the memory of the computer system of the Civil Engineering Department of Kuwait University. SAS software (SAS Statistics 1985) was utilized for processing and analyzing the data. The objective of the study was to examine the water and other drinks consumption in Kuwait.

\section{DISTRIBUTION CHARACTERISTICS OF RESPONDENTS}

\section{General Characteristics}

The social traits distribution of the sample responding to the questionnaire is presented in Table 1. These include responders' gender, nationality, age, and education level. The data in Table 1 indicate that 61.56 percent of the people surveyed had a college or higher level of formal education, more than 52 percent female and more than 73 percent were Kuwaitis. When eliminating the non-Kuwaiti, single laborers from the among the expatriate population in Kuwait, the nationality distribution of the sample conforms to expectation. The data also indicate that more than 57 percent of the people surveyed were more than 25 years of age while more than 42 percent were less than 26 years old. 


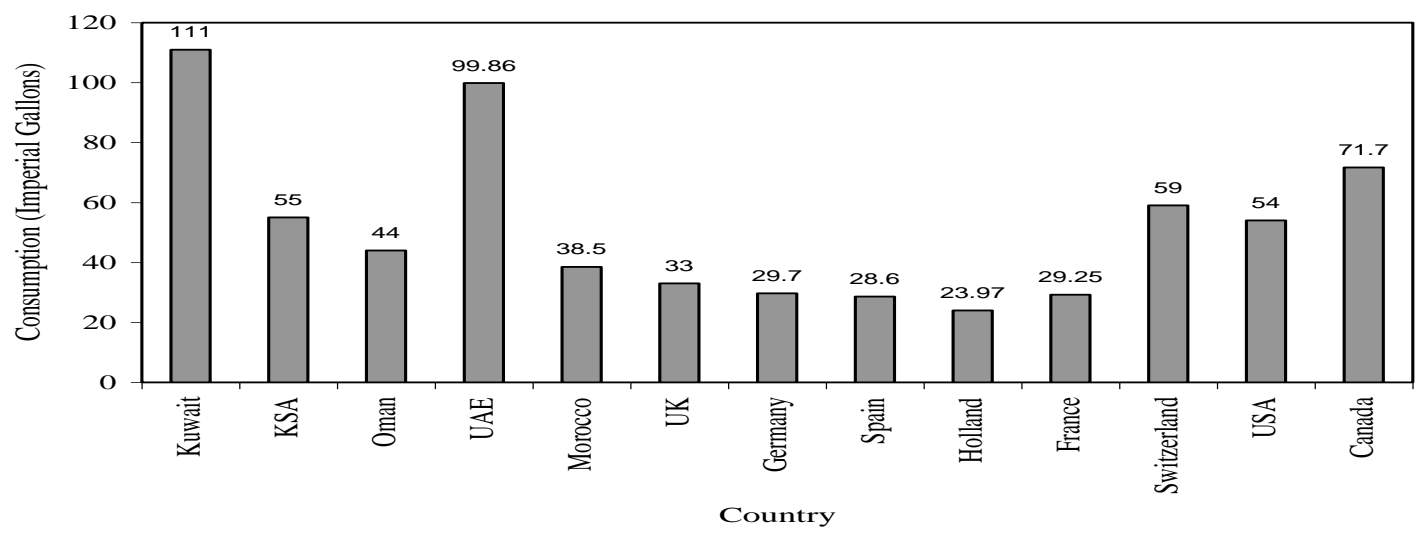

Figure 3. The yearly per capita water consumption for different countries.

Table 1: Distribution of General Characteristics of Respondents

\begin{tabular}{|c|c|c|c|}
\hline Variable Name & Frequency & Percent (\%) & Cumulative (\%) \\
\hline Gender & & & 47.56 \\
\hline Male & 975 & 47.56 & 100 \\
\hline Female & 1075 & 52.44 & 73.41 \\
\hline Nationality & & & 100 \\
\hline Kuwaiti & 1505 & 73.41 & \\
\hline Non-Kuwaiti & 545 & 26.59 & 21.37 \\
\hline Education & & & 69.07 \\
\hline High School or less & 438 & & 83.02 \\
\hline Institute & 350 & 21.37 & 100 \\
\hline College & 1065 & 17.07 & 19.51 \\
\hline Graduate Degree & 197 & 51.95 & 59.61 \\
\hline Age (year) & & 9.61 & 84.15 \\
\hline $15-20$ & 400 & & 93.95 \\
\hline $21-25$ & 466 & 19.51 & 100 \\
\hline $26-35$ & 614 & 22.73 & \\
\hline $36-45$ & 379 & 29.95 & 18.49 \\
\hline More than 45 & 191 & 9.32 & \\
\hline
\end{tabular}




\section{Water Consumption Characteristics}

Since Al-Rawdatin is the only local bottled water available in Kuwait, a question regarding its use was added to the questionnaire. In addition, data about the type of water used in the daily life of the people in Kuwait are presented in Table 2. The survey results revealed that more than 87 percent of respondents use filtering or treatment devices. Also, the data shows that 56.29 percent of the people in Kuwait use both tap and bottled water for drinking. Importantly, the survey also shows more than 400 thousands ( 20.2 percent) of the people in Kuwait report they do not drink tap water at all. The survey found several reasons for people's reluctance to rely solely on tap water and use alternatives such as bottled water and home filtration. It was found that the color of the water is the most troubling and worrisome issue to them. Fifty nine percent of the households are disturbed by color, 26 percent are disturbed by the taste of water, and 21 percent are disturbed by the impurity of the water. Notice that the total exceeds 100 percent (exactly 106 percent), which means that some people are bothered by more than one item at the same time. The survey proved that bottled water users are significantly more health-conscious than non-users; they cite health as a reason for beverage consumption twice as often as non-users. Moreover, they choose bottled water for three reasons: it's good for them, it tastes good and it's convenient. When asked about using Al-Rawadatin bottled water brand, only 31.3 percent about one third, of the respondents said they use it for their daily consumption. Interestingly, the survey revealed that 7.4 percent of the people in Kuwait use bottled water for cooking and/or for making tea and coffee. Parents with children at home, who sensitive to their family's health, stand out as being more concerned ( 85 percent) than nonparents (70 percent) about the quality of their drinking water. Parents are also somewhat more inclined to seek advice from health professionals on whether to drink filtered water or use bottled water at home. Seventy seven percent of the people in Kuwait feel that the quality of bottled water is slightly high. Forty one percent feel that it is extremely or very high, while the other 36 percent feel it is somewhat high.

\section{Characteristics of Hydrating and Dehydrating Beverages}

The consumption of hydrating, including water, and dehydrating beverages, their mean consumption rates, and frequency-based ranks are presented in Table 2. Water is the most consumed beverage in Kuwait with a mean consumption rate of 3.17 glasses/cups per day. Almost 2 cups/glasses (1.86) of tea are consumed daily. The data also revealed that, people in Kuwait consume on average one and a half (1.49) glasses/cups of juice per day, while the mean coffee consumption per day is 1.24 cups. Soft drinks and milk consumption came last with a daily mean consumption of 1.15 and 1.08 glasses/cups respectively. It is important to note that the people in Kuwait consume milk less than any other beverage. In addition, they consume a lot of beverages that contain caffeine. Research has shown that caffeine is diuretic causing the body to lose water, thereby lowering the net total of hydrating beverages. In fact, 43 percent of what Kuwaitis drink every day can cause dehydration.

\section{Knowledge Gaps}

Finally, an attempt was made to find out the level of knowledge among the people in Kuwait regarding beverages (Table 3 ). More than seventy percent (71.12 percent) of the respondents know that health and nutrition experts recommend drinking eight or more, eight-ounce glasses of water daily. However, more than fifty percent admit to drinking less than this amount. Only 25 percent claim they drink eight or more servings per day. Twenty three percent drink between 4 and 7 servings, fifteen percent drink two servings, six percent drink one serving, and nearly two percent say they do not drink water at all. People in Kuwait give a variety of reasons for not drinking enough water, with lack of time or being too busy cited as the most often, ( 25 percent). Other reasons include: disliking the taste (16 percent), preferring beverages (14 percent), forgetting (11 percent), not feeling thirsty (9 percent), no bottled water available ( 8 percent), employees unable to leave their desks for a hydration break ( 3 percent), employers worrying about too many restroom breaks ( 3 percent). Respondents were unclear about hydration being related to certain physiological conditions. Forty two percent of them are unaware that giving a child water instead of juice or regular soda may prevent childhood obesity. More than sixty percent (61.3 percent) believe that the body losses less water while sleeping. Forty three percent think that people need fewer fluids when the weather is cold than when it is warm. And nearly half ( 49 percent) do not realize that a headache may be a sign of dehydration. However, most respondents are aware of the importance of water consumption to their overall health. An overwhelming percentage of Kuwaitis ( 90 percent) know that drinking enough water is important for pregnant and 
breast-feeding women, and that water is the best choice to replace fluids after exercising. In addition, 82 percent know people should not wait until they are thirsty to drink water.

Table 2: The Consumption Of Hydrating and Dehydrating Beverages, and Their Mean Consumption Rates, and Frequency-Based Ranks

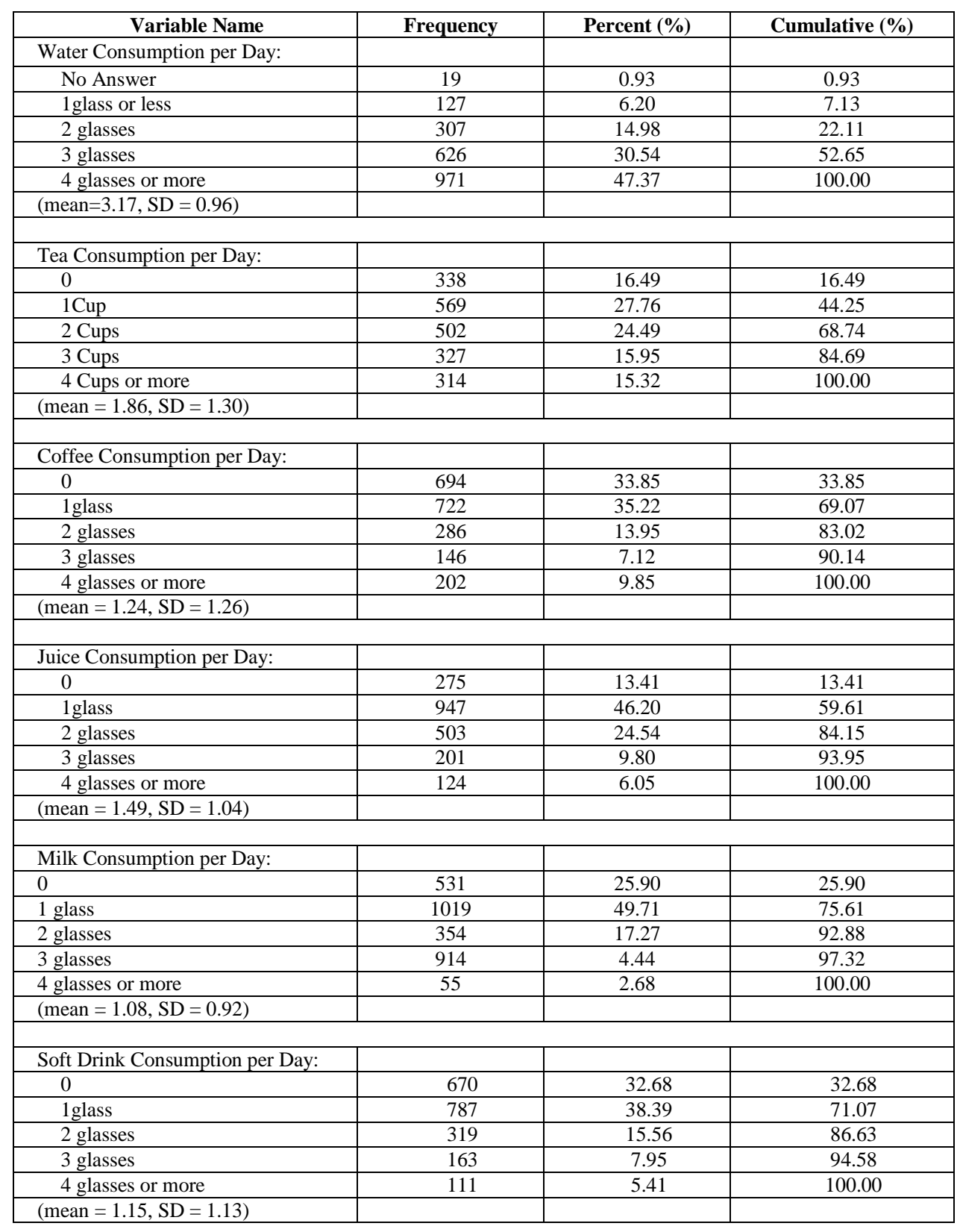

It was interesting to find out the gap of knowledge among respondents regarding the amount of water consumption recommended by health and nutrition experts. This knowledge gap varies according to gender, nationality, and education level (Table 3). The data revealed that females in Kuwait know much more (78 percent) than males (64 percent). Also, the survey revealed that 72.43 percent of Kuwaitis know about the recommended water consumption, while for non-Kuwaitis the percentage is lower (67.52 percent). When nationality and gender were 
taken into account, the data shows that the knowledge on recommended water consumption of male Kuwaitis and non-Kuwaitis was 65 percent and 18.29 percent, respectively. On the other hands, the data revealed that Kuwaiti and non-Kuwaiti females, knowledge on this issue 79 percent and 74 percent, respectively. It is noted that the gap of knowledge between males ( 46.71 percent) is very wide in comparison to the females' knowledge ( 5 percent). This can be attributed to, as was mentioned above, the incoming expatriate male workers or laborers with low level of education to the country. While most non-Kuwaiti females are highly educated with professional careers. The data shows that as the education level increases so does the level of knowledge. Fifty seven percent with a high school educational level or below know the recommend amount of water consumption set by health and nutrition experts, sixty nine percent of the people with institute educational level, and at least seventy six percent of the people with a college or higher educational level are aware of this amount.

Table 3: Cross-Reference of Knowledge of Water Consumption by Gender, Nationality and Education

\begin{tabular}{|c|c|c|c|}
\hline & \multicolumn{2}{|c|}{ Knowledge of Water Consumption per Da } & \multirow[b]{2}{*}{ Total $(\%)$} \\
\hline Variable Name & Yes $(\%)$ & No $(\%)$ & \\
\hline Total Sample Size & 71.12 & 28.88 & 100.00 \\
\hline \multicolumn{4}{|l|}{ By Gender } \\
\hline Male & 63.79 & 36.21 & 100.00 \\
\hline Female & 77.77 & 22.23 & 100.00 \\
\hline & \multicolumn{3}{|c|}{$($ Chi-Square $=48.6, \mathrm{df}=1, \mathrm{p}<0.0001)$} \\
\hline \multicolumn{4}{|l|}{ By Nationality } \\
\hline Kuwaiti & 72.43 & 27.57 & 100.00 \\
\hline Non-Kuwaiti & 67.52 & 32.48 & 100.00 \\
\hline \multicolumn{4}{|c|}{$($ Chi-Square $=0.03, \mathrm{df}=1, \mathrm{p}=0.03)$} \\
\hline \multicolumn{4}{|l|}{ By Education } \\
\hline High School or less & 56.85 & 43.15 & 100.00 \\
\hline Institute & 68.57 & 31.43 & 100.00 \\
\hline College & 75.59 & 24.41 & 100.00 \\
\hline Graduate Degrees & 83.25 & 16.75 & 100.00 \\
\hline \multicolumn{4}{|c|}{ (Chi-Square $=13.86, \mathrm{df}=3, \mathrm{p}=0.0031)$} \\
\hline \multicolumn{4}{|l|}{ By Nationality and Gender } \\
\hline Kuwaiti Male & 64.63 & 35.37 & 100.00 \\
\hline Non-Kuwaiti Male & 18.29 & 81.71 & 100.00 \\
\hline Kuwaiti Female & 78.97 & 21.03 & 100.00 \\
\hline Non-Kuwaiti Female & 73.93 & 26.07 & 100.00 \\
\hline \multicolumn{4}{|c|}{$($ Chi-Square $=0.7, \mathrm{df}=1, \mathrm{p}=0.4)$} \\
\hline \multicolumn{4}{|l|}{ By Education and Gender } \\
\hline High School or less $-\mathrm{M}$ & 52.5 & 47.46 & 100.00 \\
\hline Institute $-\mathrm{M}$ & 61.70 & 38.30 & 100.00 \\
\hline College $-\mathrm{M}$ & 66.82 & 33.18 & 100.00 \\
\hline Graduate Degrees $-\mathrm{M}$ & 77.78 & 22.22 & 100.00 \\
\hline High School or less $-\mathrm{F}$ & 61.88 & 38.12 & 100.00 \\
\hline Institute - & 76.54 & 23.46 & 100.00 \\
\hline College - F & 81.41 & 18.19 & 100.00 \\
\hline \multirow{2}{*}{ Graduate Degrees $-\mathrm{F}$} & 92.96 & 7.04 & 100.00 \\
\hline & \multicolumn{3}{|c|}{$($ Chi-Square $=44, \mathrm{df}=3, \mathrm{p}<0.0001)$} \\
\hline \multicolumn{4}{|l|}{ By Education and Nationality } \\
\hline High School or less $-\mathrm{K}$ & 58.36 & 41.64 & 100.00 \\
\hline Institute $-\mathrm{K}$ & 71.70 & 28.30 & 100.00 \\
\hline College $-\mathrm{K}$ & 76.85 & 23.15 & 100.00 \\
\hline Graduate Degrees - K & 81.45 & 18.55 & 100.00 \\
\hline High School or less - NK & 52.89 & 47.11 & 100.00 \\
\hline Institute $-\mathrm{NK}$ & 58.82 & 41.18 & 100.00 \\
\hline College - NK & 71.80 & 28.20 & 100.00 \\
\hline Graduate Degrees - NK & 86.30 & 13.70 & 100.00 \\
\hline 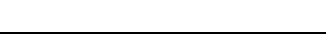 & \multicolumn{3}{|c|}{$($ Chi-Square $=0.0001, \mathrm{df}=3, \mathrm{p}=0.17)$} \\
\hline
\end{tabular}




\section{The Forecasting per capita of water consumption}

Per capita water consumption in Kuwait is increasing at an alarming rate (Figure 1). Kuwait's government heavily subsidizes water consumption. While 1000 gallons $\left(4,545 \mathrm{~m}^{3}\right)$ of water costs the Ministry of Energy KD 2.7 (K.D. $1=$ US\$ 3.3) to produce, the customer is charged KD 0.8 for it. These subsidies add a heavy burden to the already large fiscal deficit. Predictions of the future water consumption would help the government in its efforts to reform its subsidy policy and find alternative methods of reducing its deficit. Also, the water sector invests continuously in expanding its production capacity. It would be very useful indeed to form an idea of the future demand for this public utility. Therefore, a forecasting per capita water consumption is carried out. As in our case, a series of 30 observations, representing total annual water consumption in Kuwait during the period from 1970 to 2000 was collected. As seen before, Fig. 1 gives a plot of the original series. A close inspection of the figure suggests that water consumption in Kuwait experienced exponential growth over the sample period with the exception of the period 1990-1991, which was explained earlier in the paper. The series suggests, a constant proportional growth rate of approximately $8 \%$ per annum. Figure 4 shows how close the forecasted values given by the model to the actual values, the results suggest a very good fit. In addition, the equation of the forecasted values is

$\mathrm{Y}=9 \times 10^{-40} \mathrm{e}^{0.0473 \mathrm{x}} \quad,\left(\mathrm{R}^{2}=0.9739\right)$

where: $\mathrm{x}=$ year of interest.

Also, Figure 4 shows that if the consumption is left as is without imposing regulations and developing awareness, it would reach 160 IG per day by year 2010. Therefore, the Ministry of Energy and the concerned authorities have to think of ways to reduce these figures. In order to achieve these outcomes, it is critical that the Ministry of Energy utilizes all outreach mechanisms available to continue to promote dialogue, raise awareness and introduce new laws and regulations for payment collection.

\section{CONCLUSION}

Most people in Kuwait are aware of the importance of water consumption to their health. In addition, they know that health and nutrition experts recommend drinking eight-ounce or more servings of water daily. However, the majority admit to drinking less than this amount. Most people in Kuwait believe that their tap water is not safe for direct drinking. The fact that more than 87 percent of the survey respondents use filtering or treatment devices indicates a high level of basic mistrust in the safety and quality of tap water. They report that they do not drink water straight from the tap for reasons of taste, odor or health and environmental concerns. In addition to their own observations on taste, odor, and color, the people in Kuwait learn about the quality and safety of their tap water from a number of information sources. Such as, television, radio, newspapers, and magazines. In general, the media provides a greater source of information about drinking water than the Ministry of Energy.

The people in Kuwait consume a lot of dehydrating beverages that contain caffeine daily. In fact, on the average 4.25 servings of dehydrating beverages are consumed daily per person. Tea being the second most drinkable beverage after water followed by juices. More than eighty percent of the population drink at least one cup of tea a day. A quarter of the people in Kuwait do not drink milk at all. While one half of the respondents consume one glass of milk a day and the rest drink at least two glasses of milk daily. Therefore, milk is the least consumed beverage in Kuwait. Ultimately, the Ministry of Health should study this point more carefully.

The Ministry of Energy and the Government should start a public campaign advising and guiding people on consuming water. One way to make and encourage the people to reduce water consumption, is by increasing the charge rates of water use. In view of the rapidly increasing cost of water supply schemes, inflation, and the financial crises the country is going through (especially after the Gulf war), the above rates seems to be unreasonably low. In addition, the Ministry of Energy should utilize all outreached mechanisms available to continue to promote dialogue, raise awareness, and promote confidence. 


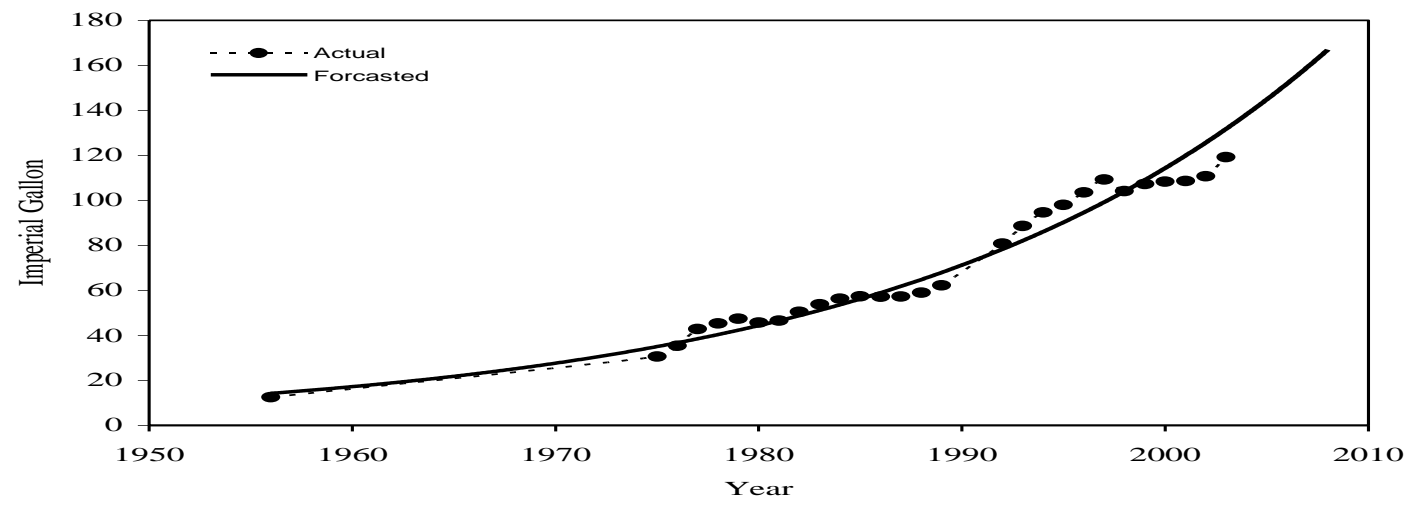

Figure 4. Consumption of water per capita per day (1956-2003).

\section{Suggestions for Future Research}

Since water is a scarce commodity in Kuwait coupled with enormous increase of per capita consumption. Thus, there should be a research on exploring other sources of water usage. One such way, is the investigation the usage of treated wastewater. In many parts of the world, secondary treated wastewater is used for irrigation. In fact, tertiary treated effluents are produced in Kuwait. Such high quality effluents can be used comfortably for irrigation. Other research can focus on ways to consume water.

\section{REFERENCES}

1. Alhumoud, J. M. and Al-Ghusain, I. Hosehold demand for water: A case study in Kuwait. Kuwait Journal of Science and Engineering, Vol. 30, No. 1, pp. 197-211, 2003.

2. Alhumoud, J. M. Water consumption evaluation in Kuwait. Journal of Water Supply: Research and Technology-AQUA (IWA), 51.8, pp. 483-488, 2002.

3. Al-Sofi, M.A., Water scarcity-The challenge of the future Desalination, Vol. 98, pp. 425-435, 1994.

4. Al-Zubari, W.K., Towards the Establishment of a Total Water Cycle Management and Re-use Program in the GCC Countries Desalination, Vol. 120, pp. 3-14, 1998.

5. KEPS, Kuwait Environment Protection Society, Water...Problem, The Environment, No. 228, pp. 18-21, 2004.

6. Koushki, P. A. and Alhumoud, J. M., Evaluation of reported and measured composition of household solid waste in Kuwait, Practice Periodicals of Hazardous, toxic, and radioactive waste management, ASCE. Vol. 6, No. 3, pp. 204-208, 2002. 
7. MOP, Ministry of Planning, Annual Statistical Abstract, edition 38, 2003.

8. Omar, S.S., Alyaqub, A \& Senay, Y., Geology and Groundwater Hydrology of the State of Kuwait, Gulf Arabian Penin. Stud., Vol. 1, pp. 9-51, 1996.

9. MPW, Ministry of Public Works (2003) Total cost of wastewater treatment. Statistical Book.

10. MEW, Ministry of Electricity \& Water, Statistical Year Book (Water). Edition 28 "B", 2003.

11. SAS/ETS Software: Applications Guide 1. Time series Modeling and Forecasting, Financial Reporting, and Loan Analysis. Version 6, $1^{\text {st }}$ Edition. Cary, N.C. USA, 1991.

12. Walpole, R.E. and Myers, R.J. Probability and statistics for engineers and scientists. $3^{\text {rd }}$ edition, Macmillan publishing Co., New York, USA, 1985.

\section{NOTES}




\section{NOTES}

